\title{
Removal of filling material using rotating or reciprocating systems with or without solvent: microCT analysis
}

\section{Bárbara Maria BIS(a)}

Yara Teresinha Corrêa SILVA-SOUSA ${ }^{(a)}$

Luciana Martins Domingues de MACEDO(a) $^{(0)}$

Orestes Pereira OLIVEIRA(a)

Edson ALFREDO(a) (iD)

Graziela Bianchi LEONI(a) (D)

Fuad Jacob Abi RACHED-JUNIOR(a)

(a) Universidade de Ribeirão Preto, School of Dentistry, Department of Endodontics, Ribeirão Preto, SP, Brazil.

Declaration of Interests: The authors certify that they have no commercial or associative interest that represents a conflict of interest in connection with the manuscript.

Corresponding Author:

Fuad Jacob Abi Rached Junior

E-mail: rached-junior@hotmail.com

htrps://doi.org/10.1590/1807-3107bor-2021.vol35.0117

Submitted: April 9, 2020

Accepted for publication: June 2, 2021

Last revision: July 12, 2021
Abstract: This study evaluated by the efficacy of rotary and reciprocating systems to remove filling material by micro-CT. Sixty human canines were instrumented up to F3 by ProTaper Universal system and filled with AH Plus/ gutta-percha. Specimens were submitted to 1,200 thermal cycles, scanned by microCT SkyScan 1176 and randomly distributed in groups according to the filling material removal protocol $(\mathrm{n}=10)$ : ProTaper Universal, ProTaper Universal/ xylol, ProTaper Next, ProTaper Next/xylol, Reciproc and Reciproc/ xylol. After filling removal, specimens were analyzed by microCT to separately verify the presence of gutta-percha and sealer remnants. The data $\left(\mathrm{mm}^{3}\right)$ were analyzed by two way ANOVA and Tukey's test (5\%). For the remaining gutta-percha, the use of xylol provided the highest values for Reciproc $(7.60 \pm 0.73)$, which was statistically different from the other groups $(p<0.05)$ that presented lower values and were statistically similar to each other ( $p>0.05)$. For the remaining sealer, xylol provided the highest values $(21.25 \pm 6.94)$ different $(\mathrm{p}<0.05)$ from the use of instruments alone (11.47 \pm 9.45$)$. ProTaper Next presented the lowest values $(8.16 \pm 1.37)$ for the remaining sealer, different $(\mathrm{p}<0.05)$ from that of Reciproc $(24.67 \pm 6.32)$. The qualitative analysis revealed that all groups presented some remaining root filling material, with the highest volumes presented by Reciproc and Reciproc/xylol. In conclusion the rotary systems provided greater removal of filling material regardless of the use of xylol. The use of xylol negatively interfered with the action of the reciprocating system in the removal of the gutta-percha and sealer.

Keywords: Endodontics; Retreatment.

\section{Introduction}

The removal of filling material can be facilitated by the crosssectional design, kinematics of the instruments, ${ }^{1}$ and the use of solvents, such as xylol. ${ }^{2}$ Rotary and reciprocating instruments, whether associated with solvents or not, have been evaluated during endodontic retreatment, such as systems ProTaper retreatment (Dentsply-Sirona, Ballaigues, Switzerland), ProTaper Universal (Dentslpy-Sirona, Ballaigues, Switzerland), in order to facilitate the removal of filling material and 
residual debris from inside the root canal. ${ }^{3}$ However, in vitro research has reported that these protocols do not completely remove the filling material from the canal, owing to difficulties associated with touching all the walls of the root canals, due to the mass of these systems being centralized. ${ }^{4}$

To overcome this limitation, the ProTaper Next rotary system (Dentsply-Sirona, Ballaigues, Switzerland) was developed, which uses NiTi M-wire alloy to manufacture instruments with turns of variable sizes and rectangular cross-section; its main feature being the eccentric kinematics that can allow for a greater cleaning capacity and modeling. ${ }^{5}$ However, studies show that this system is not effective in the complete removal of filling material from the interior of the canal, in the endodontic retreatment. ${ }^{6-9}$ It is worth mentioning that in these studies, the ProTaper Next system was used without association with any type of organic solvent.

In clinical practice, different organic solvents have been used as auxiliaries or main methods to dissolve filling material, the most commonly used being chloroform and xylol. Unlike chloroform, xylol is not considered a carcinogen and has a superior solvency capacity than orange oil, chloroform, and eucalyptol..$^{10}$ The literature also reports that solvents can morphologically alter the dentin surface, ${ }_{11}^{.1}$ their use can facilitate the action of instruments and decrease the risk of diversion and perforations. ${ }^{10}$

Considering that during endodontic retreatment, the action of instruments on the root canal wall is a primary factor for the removal of filling material and that xylol may favor the softening of gutta-percha, this study aimed to evaluate the effectiveness of rotary and reciprocating systems associated with or without xylol in the removal of the filling material, using micro-computed tomography (micro-CT). The null hypothesis was that xylol would favor the complete removal of filling material from inside the root canal.

\section{Methodology}

This study was submitted to and approved by the Research Ethics Committee institutional (CAAE: 74990217.8.0000.5498).

\section{Preliminary micro-CT scanning}

The total sample size for this study was calculated on the basis of a previous research study that also used micro-computed tomography (micro-CT) scans to evaluate the removal of filling material by using rotary systems. ${ }^{11}$

\section{Sample selection}

Roots of human maxillary canines were scanned to standardize the samples for internal anatomy and root canal volume using a SkyScan 1176 micro-CT scanner (Bruker-microCT, Kontich, Belgium) with resolution $9 \mu \mathrm{m}, 90 \mathrm{KV}$ e $276 \mu \mathrm{A}$. Sixty fully-formed roots with a single canal and no calcifications, free of pulp nodules, internal resorption, root fracture, and previous root canal treatment were selected.

\section{Root canal treatment}

The biomechanical preparation was performed using the ProTaper Universal system (Dentsply Maillefer, Ballaigues, Switzerland) according to the: SX (300 gcm torque, $350 \mathrm{rpm}$ ), S1 (300 gcm torque, $350 \mathrm{rpm}), \mathrm{S} 2$ (100 gcm torque, $250 \mathrm{rpm}), \mathrm{F} 1(250 \mathrm{gcm}$ torque, $300 \mathrm{rpm}), \mathrm{F} 2$ (200 gcm torque, $250 \mathrm{rpm}$ ) and F3 (200 gcm torque, $250 \mathrm{rpm}$ ), powered by a VDW Silver motor (VDW, GmbH, Munchen, Germany) coupled in the VDW motor (VDW, Munich, Germany). The root canal was irrigated with $2 \mathrm{~mL}$ of $2.5 \% \mathrm{NaOCl}$ at each instrument change and the final irrigation with $2 \mathrm{~mL}$ of $17 \%$ EDTA for $5 \mathrm{~min}$. Root canal filling was performed with AH Plus sealer (Dentsply-Maillefer, Ballaigues, Switzerland) and gutta-percha cones using the lateral condensation technique. The sealer, mixed according to the manufacturer's instructions, was applied to the canal with a size 25 lentulo spiral (Dentsply Maillefer, Ballaigues, Switzerland) and then a main cone F3 (Dentsply Maillefer, Ballaigues, Switzerland) was introduced to the WL. A size 25 finger spreader (Dentsply Maillefer, Ballaigues, Switzerland) was introduced vertically to create space for the insertion of the accessory gutta-percha cone (Dentsply-Maillefer, Ballaigues, Switzerland). After removal of the finger spreader, an accessory guttapercha cone coated with sealer was introduced into the canal immediately. This procedure was repeated three times for each specimen. 


\section{Thermocycling}

After three times the setting time $(480 \mathrm{~min})$ of $\mathrm{AH}$ Plus sealer, the specimens were submitted to 1200 cycles of thermocycling, with the purpose to mimic the aging of the filling material for a period corresponding to 12 months ${ }^{12}$. Thermocycling was performed with distilled and deionized water with a temperature varying between $5^{\circ}$ and $55^{\circ} \mathrm{C}$, for 3 days, with an immersion time of $30 \mathrm{~s}$, at each temperature, with transfer time between each temperature of $2 \mathrm{~s} .{ }^{12}$

\section{First micro-CT scanning}

The specimens were subjected to the second scanning in a micro-CT scanner (SkyScan 1176) with the following parameters: resolution $9 \mu \mathrm{m}$, $360^{\circ}$ rotation, $0,7^{\circ}$ rotation step, frames $2,0.1 \mathrm{~mm}$ copper filter $(90 \mathrm{KV}$ e $276 \mu \mathrm{A})$, with a dentin threshold with a interval of 24-57, gutta-percha threshold between 129-213 and sealer 213-255. The images were reconstructed by NRecon software (Bruker-microCT, Kotich, Belgium), by using the modified Feldkamp cone beam reconstruction algorithm. The volume of the gutta-percha and sealer was measured using the CTAn software, without considering $1 \mathrm{~mm}$ of the root apex.

\section{Experimental groups}

The specimens were distributed according to the endodontic retreatment protocol: ProTaper Universal, ProTaper Universal/xylol, ProTaper Next, ProTaper Next/xylol, Reciproc and Reciproc/xylol. It is worth noting that the instruments were coupled to the VDW motor and used according to the system in each experimental group.

\section{ProTaper Universal group}

The removal of the filling material was initially performed using the instruments from the ProTaper retreatment system (Maillefer Instruments S. A., Ballaigues, Switzerland): D1, D2 and D3 coupled to the VDW motor, being driven with traction movements against the walls up to the working length. The D1 instrument was used to remove the filling material in the cervical third, D2 in the middle and D3 in the apical as recommended by the manufacturer with $500 \mathrm{rpm}$ and with a torque of $3 \mathrm{Ncm}$. To achieve a better enlargement of the root canal and instruments F4 (200 gcm torque, $250 \mathrm{rpm}$ ) and F5 (200 gcm torque, $250 \mathrm{rpm}$ ) of the ProTaper Universal system. The root canal was irrigated at each instrument change, with 2 $\mathrm{mL}$ of $2.5 \% \mathrm{NaOCl}$ (Asfer, São Caetano do Sul, Brazil) using the NaviTip syringe (Ultradent Products Inc., South Jordan, USA), then aspirated and flooded with $2 \mathrm{~mL}$ of $17 \%$ EDTA (Asfer, São Caetano do Sul, Brazil) for $5 \mathrm{~min}$. In the end, the root canal was irrigated with $5 \mathrm{~mL}$ of distilled and deionized water and after aspiration, dried with absorbent paper cones (Dentsply-Sirona, Ballaigues, Switzerland).

\section{ProTaper Universal/ xylol group}

The removal of the filling material in this group was performed according to the description used for Group 1, with the addition of the xylol solvent (Bioquimica Industria Farmaceutica, São José do Rio Preto, Brazil). One drop of xylol was dispensed in a dappen bottle (Golgran Ind. Com. Instr. Odontol., São Caetano do Sul, Brazil) and, at each instrument change, with the aid of a pair of clinical forceps (Duflex, S. S. White artigos dentarios Ltda., Rio de Janeiro, Brazil), was delivered at the root canal entrance. The root canal was irrigated at each instrument change with $2 \mathrm{~mL}$ of $2.5 \% \mathrm{NaOCl}$ using the NaviTip syringe, then aspirated and flooded with $2 \mathrm{~mL}$ of $17 \%$ EDTA for $5 \mathrm{~min}$. In the end, the root canal was irrigated with $5 \mathrm{~mL}$ of distilled and deionized water and after aspiration, dried with absorbent paper cones.

\section{ProTaper Next group}

The ProTaper Next system (Dentsply Sirona, Ballaigues, Switzerland) was used to remove the material, in the following sequence: $\mathrm{X} 1, \mathrm{X} 2, \mathrm{X} 3, \mathrm{X} 4$ and $X 5$. These instruments were used at $500 \mathrm{rpm}$ and $3 \mathrm{Ncm}$ of torque in a continuous rotary motion ${ }^{6}$. The instrument was inserted with an insertion/ removal movement in the filling material, with an amplitude of approximately $3 \mathrm{~mm}$ and light pressure against the walls. The irrigation was performed at each instrument change, with $2 \mathrm{~mL}$ of $2.5 \% \mathrm{NaOCl}$ using the NaviTip syringe, followed by $2 \mathrm{~mL}$ of $17 \%$ EDTA for $5 \mathrm{~min}$. In the end, the root canals were irrigated with $5 \mathrm{~mL}$ of distilled and deionized water, and after aspiration, dried with absorbent paper cones. 


\section{ProTaper Next/ xylol group}

The sequence of removal of the filling material was carried out according to the description for group 5, adding xylol solvent. One drop of xylol was dispensed in a dappen bottle and, at each instrument change, with the aid of a pair of clinical forceps, was delivered at the root canal entrance. The irrigation was performed at each instrument change, with $2 \mathrm{~mL}$ of $2.5 \% \mathrm{NaOCl}$ using the NaviTip syringe, followed by $2 \mathrm{~mL}$ of $17 \%$ EDTA for $5 \mathrm{~min}$. In the end, the root canals were irrigated with $5 \mathrm{~mL}$ of distilled and deionized water, and after aspiration, dried with absorbent paper cones.

\section{Reciproc group}

The removal of the filling material was performed with the R50 instrument (VDW, Munich, Germany) from the Reciproc system (VDW, Munich, Germany), activated in reciprocating motion generated by a 6:1 contra-angle handpiece (Sirona, Bensheim, Germany) powered by an electric motor (VDW Silver, Munich, Germany), in Reciproc all mode, responsible for the reciprocating movement, an in the counterclockwise (cut) and clockwise direction (release of the instrument). The instrument was inserted with an insertion/removal movement in the filling material, with an amplitude of approximately $3 \mathrm{~mm}$ and light pressure against the walls. After the third movement, the instrument was removed from the root canal, cleaned with sterile gauze and the root canal irrigated with $2 \mathrm{~mL}$ of $2.5 \% \mathrm{NaOCl}$. The procedure was repeated until the instrument attained the working length, so that the root canal could be flooded with $2 \mathrm{~mL}$ of $17 \%$ EDTA for $5 \mathrm{~min}$. In the end, they were irrigated with $5 \mathrm{~mL}$ of distilled and deionized water, and after aspiration, dried with absorbent paper cones.

\section{Reciproc/ xylol group}

The filling material was removed as described for group 3. However, a drop of xylol was dispensed in a dappen bottle and with the aid of clinical forceps, was delivered at the root canal entrance. The instrument was inserted with an insertion/removal movement in the filling material, with an amplitude of approximately $3 \mathrm{~mm}$ and light pressure against the walls. Before the third movement, another drop of xylol was delivered at the root canal entrance. The instrument was inserted in the root canal and activated again until the working length, before being removed. The root canal was irrigated with $2 \mathrm{~mL}$ of $2.5 \% \mathrm{NaOCl}$ using the NaviTip syringe, followed by 2 $\mathrm{mL}$ of $17 \%$ EDTA for $5 \mathrm{~min}$. In the end, the root canal was irrigated with $5 \mathrm{~mL}$ of distilled and deionized water, and after aspiration, dried with absorbent paper cones.

It is worth mentioning that during endodontic retreatment, the total volume of $2.5 \% \mathrm{NaOCl}$ was standardized in $10 \mathrm{~mL}$ for each specimen, in all experimental groups.

\section{Second micro-CT scanning}

After removing the material obtained from different experimental groups, the specimens were submitted to the second scan with the same parameters used in the first scan.

\section{Micro-CT evaluation}

For quantitative analysis the images were reconstructed using NRecon software (BrukermicroCT, Kotich, Belgium), and the CTAn software (Bruker-microCT, Kontich, Belgium) was used to measure the initial and remaining volumes $\left(\mathrm{mm}^{3}\right)$ separately of the gutta-percha and the sealer. The images were superimposed and the remaining was calculated in relation to the initial volume of guttapercha and sealer.

The qualitative analysis of the remaining gutta-percha and sealer was performed by three calibrated examiners, through visual inspection of the reconstructed micro-CT images.

\section{Statistical analysis}

The data $\left(\mathrm{mm}^{3}\right)$ of the remaining gutta-percha and remaining sealer that adhered to the root canal wall were submitted to preliminary statistical tests, in order to verify the normality of the sample distribution. After confirmation of homogeneity (Levene test) and normality (Kolmogorov-Smirnov test), parametric statistical tests of analysis of variance (ANOVA) were used to verify the existence of differences between the factors analyzed, and the complementary Tukey 
test was used to determine the difference between groups, with a $5 \%$ significance level $(\alpha=0.05)$. Statistical analysis was performed using the SPSS software (Statistical Package for the Social Sciences; SPSS Inc., Chicago, USA).

\section{Results}

\section{Quantitative analysis}

For the remaining gutta-percha, there was a statistically significant difference $(p<0.05)$ between the instrumentation systems, the use of solvent, and the interaction between these two factors $(\mathrm{p}<0.05)$. The use of xylol did not favor the removal of guttapercha $(\mathrm{p}>0.05)$. Also, it provided the highest mean values when associated with the Reciproc $(7.60 \pm 0.73)$ $(\mathrm{p}<0.05)$, as observed in Table 1.

For the remaining sealer, there was a statistically significant difference between the use of the xylol and the instrumentation systems $(\mathrm{p}<0.05)$, however, there was no effect on the interaction between these factors $(p>0.05)$. The use of xylol provided the highest values $\left(\mathrm{mm}^{3}\right)$ of the remaining sealer $(21.25 \pm 6.94)$, which were significantly different $(p<0.05)$ from the values obtained with the use of instruments alone (11.47 \pm 9.45). Thus, ProTaper Next $(8.16 \pm 1.37)$ presented the lowest mean value $\left(\mathrm{mm}^{3}\right)$ of the remaining sealer, which was significantly different $(p<0.05)$ from the mean value of Reciproc (24.67 \pm 6.32 ). ProTaper Universal (16.24 \pm 3.11$)$ presented intermediate values $\left(\mathrm{mm}^{3}\right)$, and it was statistically similar $(\mathrm{p}>0.05)$ to ProTaper Next and Reciproc (Table 2).

\section{Qualitative analysis}

The qualitative analysis allowed us to observe that all the root canals were completely filled.

Table 1. Means and standard deviations of the volume $\left(\mathrm{mm}^{3}\right)$ of the remaining gutta-percha in the root canal wall.

\begin{tabular}{lccc}
\hline \multirow{2}{*}{ Solvent } & \multicolumn{3}{c}{ Instruments system } \\
\cline { 2 - 4 } & $\begin{array}{c}\text { ProTaper } \\
\text { Universal }\end{array}$ & ProTaper Next & Reciproc \\
\hline without xylol & $0,23 \pm 0,12^{a}$ & $0,85 \pm 0,50^{a}$ & $0,81 \pm 0,39^{a}$ \\
with xylol & $2,47 \pm 0,82^{a}$ & $0,28 \pm 0,15^{a}$ & $7,60 \pm 3,73^{b}$ \\
\hline
\end{tabular}

*Different letters indicate a statistically significant difference $(p<0.05)$. Tukey test.
In general the qualitative analysis allowed us to observe that ProTaper Universal (Figure A) and ProTaper Next (Figure C) provided specimens with a smaller remnant of gutta-percha and/ or sealer adhered to the root canal wall. The ProTaper Universal/xylol (Figure B) and ProTaper Next/ xylol (Figure D) presented a greater amount of gutta-percha and sealer remaining on the root canal wall. Reciproc (Figure E) and Reciproc/xylol (Figure F) showed a greater amount of gutta-percha and sealer. The Reciproc/xylol (Figure F) showed specimens with a large amount of gutta-percha and sealer along the root canal, when compared to ProTaper Universal/xylol (Figure B) and ProTaper Next/xylol (Figure D).

\section{Discussion}

The null hypothesis of this study was rejected. The use of xylol did not favor the complete removal of gutta-percha and sealer from the interior of the root canal, during endodontic retreatment.

The use xylol as a solvent is recommended in clinical practice because it promotes the softening of gutta-percha; thus, it facilitates the penetration of the instrument inside the filling material, reducing the risk of perforations during removal of the filling material. ${ }^{13}$ However, the use of solvents alters the physical and chemical characteristics of the filling material and can reduce the effectiveness of the instrumentation. ${ }^{14}$ The gutta-percha softened by the solvent forms a thin film that adheres to the surface of the root canal wall, which is difficult to remove, even with the enlargement promoted by the instruments. ${ }^{14,15}$ This observation can explain the findings of the present study, in which no filling

Table 2. Means and standard deviations of the volume $\left(\mathrm{mm}^{3}\right)$ of the sealer remaining in the root canal wall after different instrumentation systems.

\begin{tabular}{lc}
\hline Instrumentation system & Mean \pm SD \\
\hline ProTaper Universal & $16,24 \pm 13,11^{\mathrm{a}, \mathrm{b}}$ \\
ProTaper Next & $8,16 \pm 8,37^{\mathrm{a}}$ \\
Reciproc & $24,67 \pm 6,32^{\mathrm{b}}$ \\
\hline
\end{tabular}

*Different letters indicate a statistically significant difference $(p<0.05)$. Tukey's test. 


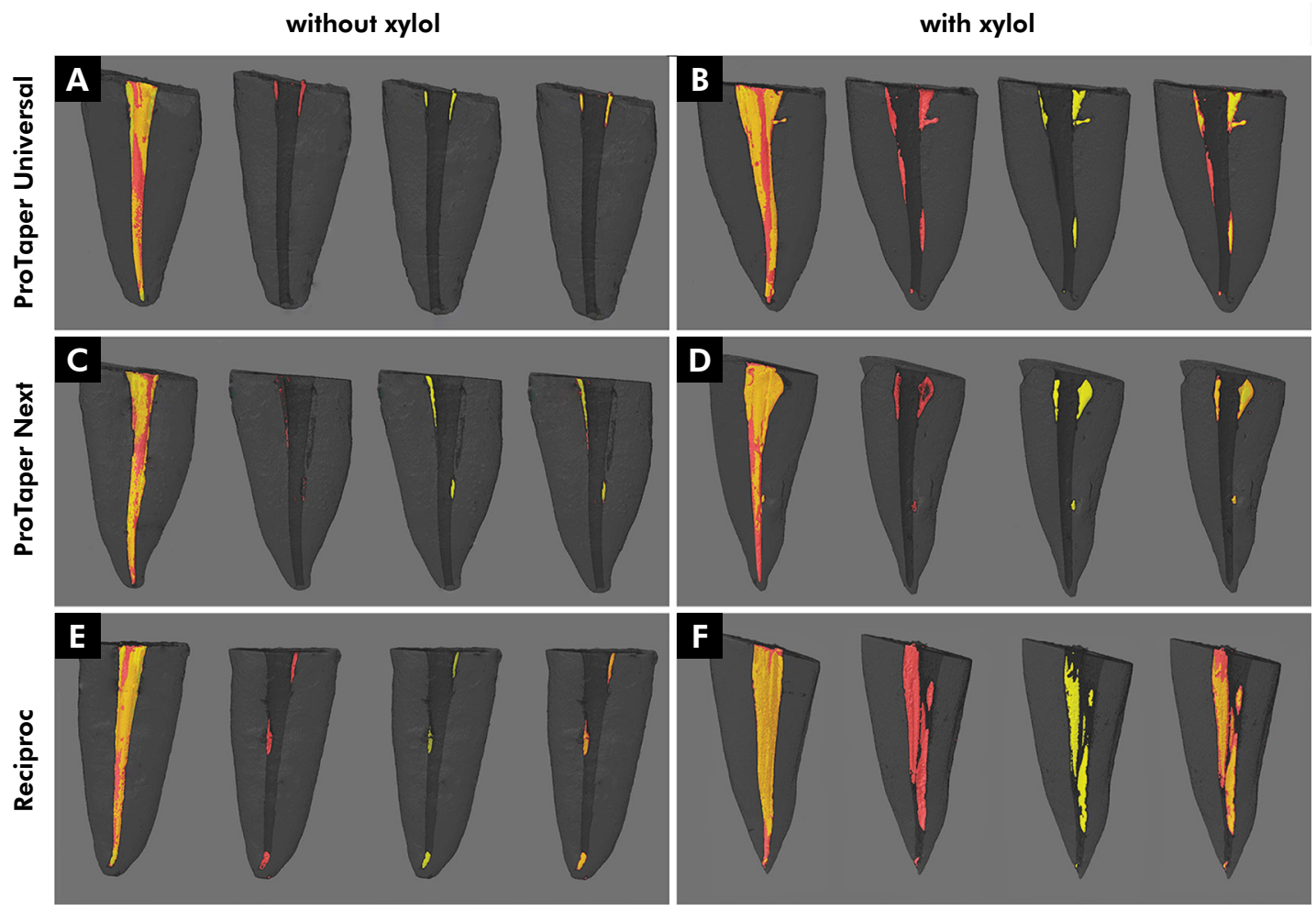

Figure. Three-dimensional illustrative images of the experimental groups. Sequence from left to right shows: filled specimen, remnant of gutta-percha, remnant of sealer and the overlap of the remnant of gutta-percha and sealer.

material removal protocol was able to completely remove the filling material from the root canal, as observed in the qualitative and quantitative analysis in micro-CT.

Micro-CT has been the method used to determine the internal anatomy of the root canal, ${ }^{16}$ the shaping of the root canal, ${ }^{17}$ the volume of filling material required, as well as the remaining filling material after different endodontic retreatment techniques. ${ }^{18}$ According to Yürüker et al., ${ }^{19}$ this is a method that has limitations, such as the lengthy scanning and analysis. However, it is a reliable method for threedimensional evaluation; also, depending on the microtomograph model and the parameters used, it allows for the differentiation of the volume of gutta-percha and sealer that adhered to the root canal wall. In the present study, the SkyScan 1176 microtomograph was used with different parameters for dentin, gutta-percha and sealer, which enabled a volumetric analysis of the remainder that adhered to the root canal wall. Another aspect that deserved to be elucidated in this study is thermocycling, which mimicked in vitro the aging behavior of the filling material that occurs in clinical practice, ${ }^{12}$ this should be recommended in future studies on endodontic retreatment.

Another aspect of the methodology that was supposed to be elucidated is the new instrumentation, where Rödig et al. ${ }^{20}$ reported the need to complement biomechanical preparation with instruments of larger caliber during endodontic retreatment. In this regard, studies ${ }^{21,22}$ have demonstrated that the enlargement of the root canal, promoted by instrumentation after unblocking, with larger caliber instruments, reduces the amount of remaining filling material, and still provides enough space for the hydraulic effect of the irrigating solution to be efficient, while helping to remove debris from the filling material. ${ }^{23}$ Thus, in this study, the use of larger caliber instruments, such as files F4 and F5 of the ProTaper Universal system, was recommended after using the ProTaper retreatment system. 
In general, it is believed that the enlargement promoted by rotary (up F5 or X5) or reciprocating (R50) instruments provided less gutta-percha and sealer when they were not associated with the xylol solvent, with the exception of Reciproc which had a higher amount of gutta-percha (in the apical third), and sealer (in the cervical, middle and apical thirds), when compared to ProTaper Universal and ProTaper Next, which can be confirmed by means of quantitative three-dimensional analysis on micro-CT. However, it is noteworthy that, although the use of xylol did not significantly favor the removal of gutta-percha, there was a reduction in mean values when associated with rotary systems, probably due to the physical and chemical changes it promotes in the filling material. However, they can also be explained by characteristics of the instruments; that is, by their cross-section and kinematics. ${ }^{4,5}$

The ProTaper Universal rotary system consists of two types of instruments called modelers (SX, S1, and S2) and finishing (F1 a F5). In this system, one fact that might have favored greater removal of the filling material is the convex triangular crosssection of the instruments, F3, F4, and F5, which present cross-sections with two different shapes along their helical rods: from the tip to $12 \mathrm{~mm}$ above, there is a concave triangular cross-section and in the rest of the stem up to D16, there is a convex triangular cross-section with short pitch (helix angle between 30 and $\left.35^{\circ}\right)^{6}$. According to Bonaccorso et al., ${ }^{24}$ the greater the helix angle, the more efficient the filing (scraping) action of the endodontic instrument on the root canal wall, promoting enlargement. In this study, this characteristic was translated into less remnant of filling material (gutta-percha and sealer) adhered to the root canal wall. However, Crozeta et al. ${ }^{18}$ found a high percentage of remaining filling material when the ProTaper Universal system was used. This divergence of results is probably a consequence of the difference in methods employed, as these authors did not recommend the enlargement of the root canal. In the present study, in all specimens, the root canals were widened, according to the selection of the systems in which the wear caused by the different instruments was standardized around $200 \mu \mathrm{m}$, as suggested by Rödig et al. ${ }^{20}$

The main characteristic of the ProTaper Next system is the rectangular cross-section, edges with varying taper, eccentric kinematics, that is, with its decentralized mass, which according to the manufacturer allows for greater efficiency in modeling the root canal. On the other hand, Elnaghy ${ }^{5}$ speculated that the decentralization of the mass might reduce the area of contact between the instrument and the root canal wall, which in the present study would probably result in a higher percentage of remaining filling material (gutta-percha and sealer) adhered to the root canal wall. Another study compared the removal of filling material from the ProTaper Next system to other rotary systems (ProFile Vortex) and found that there was no significant difference, probably due to the characteristic of the MWire alloy of these instruments, as well as due to the continuous rotary movement. ${ }^{9,25}$ In contrast, both the qualitative and the quantitative analyses in the present study revealed less remnant of filling material (gutta-percha and sealer), probably due to the $200 \mu \mathrm{m}$ enlargement promoted by their instruments.

Reciproc systems different from the ProTaper Universal and ProTaper Next systems have two cutting blades and an " $\mathrm{S}$ " shaped cross-section, which promote less stress from the instrument to the root canal walls. ${ }^{26}$ This feature may explain the difficulty in removing gutta-percha apical third even with the enlargement made possible by the R50 instrument. Automated balanced pressure without pressure of the reciprocating motion kinematics promotes greater apical extrusion than rotary instruments. ${ }^{27}$ Following this same reasoning, it can be assumed that the lower tension of the instrument to the root canal wall combined with its reciprocal kinematics filling material for the apical region, thus providing a greater amount of remnant than the ProTaper Universal and ProTaper Next systems, as can be observed in the qualitative analysis. However, Nevares et al. ${ }^{6}$ compared ProTaper Next to Reciproc, and observed similar results in the removal of filling material, which we did not observe in our study. It can be explained by the use of the $\mathrm{R} 25$ reciprocating instrument, which probably 
should not have displaced and compacted as much material to the walls of the root canal as the R50 used in our study.

In an attempt to minimize the amount of filling material remaining, the enlargement of the root canal was recommended; however, it can reduce the thickness of the dentin, and consequently, weaken the dental root. Thus, additional studies are needed to elucidate the dentin wear caused by the instruments in endodontic retreatment, as well as to evaluate new strategies for the total removal of the filling material.

\section{Conclusions}

In conclusion the rotary systems provided greater removal of filling material regardless of the use of xylol. The use of xylol negatively interfered with the action of the reciprocating system in the removal of the filling material.

\section{References}

1. Giuliani V, Cochetti R, Pagavino G. Efficacy of ProTaper universal retreatment files in removing filling materials during root canal retreatment. J Endod. 2008 Nov; 34(11):1381-4. J Endod. https://doi.org/10.1016/i.joen.2008.08.002

2. Oyama KO, Siqueira EL, Santos M. In vitro study of effect of solvent on root canal retreatment. Braz Dent J. 2002;13(3):208-11. https://doi.org/10.1590/S0103-64402002000300014

3. Abramovitz I, Relles-Bonar S, Baransi B, Kfir A. The effectiveness of a self-adjusting file to remove residual gutta-percha after retreatment with rotary files. Int Endod J. 2012 Apr;45(4):386-92. https://doi.org/10.1111/j.1365-2591.2011.01988.x

4. Bago I, Suk M, Katić M, Gabrić D, Anić I. Comparison of the effectiveness of various rotary and reciprocating systems with different surface treatments to remove gutta-percha and an epoxy resin-based sealer from straight root canals. Int Endod J. 2019 Jan;52(1):105-13. https://doi.org/10.1111/iej.12985

5. Elnaghy AM. Cyclic fatigue resistance of ProTaper Next nickel-titanium rotary files. Int Endod J. 2014 Nov;47(11):1034-9. https://doi.org/10.1111/iej.12244

6. Nevares G, Albuquerque DS, Freire LG, Romeiro K, Fogel HM, Santos M, et al. Efficacy of ProTaper NEXT compared with reciproc in removing obturation material from severely curved root canals: a micro-computed tomography study. J Endod. 2016 May;42(5):803-8. https://doi.org/10.1016/i.joen.2016.02.010

7. Özyürek T, Demiryürek ËÖ. Efficacy of Different Nickel-Titanium Instruments in Removing Gutta-percha during Root Canal Retreatment. J Endod. 2016 Apr;42(4):646-9. https://doi.org/10.1016/i.joen.2016.01.007

8. Martins MP, Duarte MA, Cavenago BC, Kato AS, Bueno CES. Effectiveness of the ProTaper next and reciproc systems in removing root canal filling material with sonic or ultrasonic irrigation: a micro-computed tomographic study. J Endod. 2017 Mar;43(3):467-71. https://doi.org/10.1016/i.joen.2016.10.040

9. Delai D, Jardine AP, Mestieri LB, Boijink D, Fontanella VR, Grecca FS, et al. Efficacy of a thermally treated single file compared with rotary systems in endodontic retreatment of curved canals: a micro-CT study. Clin Oral Investig. 2019 Apr;23(4):1837-44. https://doi.org/10.1007/s00784-018-2624-6

10. Martos J, Bassotto AP, González-Rodríguez MP, Ferrer-Luque CM. Dissolving efficacy of eucalyptus and orange oil, xylol and chloroform solvents on different root canal sealers. Int Endod J. 2011 Nov;44(11):1024-8. https://doi.org/10.1111/j.1365-2591.2011.01912.x

11. Palhais M, Sousa-Neto MD, Rached-Junior FJ, Amaral MC, Alfredo E, Miranda CE, et al. Influence of solvents on the bond strength of resin sealer to intraradicular dentin after retreatment. Braz Oral Res. 2017 Jan;31(0):e11. https://doi.org/10.1590/1807-3107bor-2017.vol31.0011

12. Botega DM, Sanchez JL, Mesquita MF, Henriques GE, Consani RL. Effects of thermocycling on the tensile bond strength of three permanent soft denture liners. J Prosthodont. 2008 Oct;17(7):550-4. https://doi.org/10.1111/i.1532-849X.2008.00342.x

13. Topçuoğlu HS, Düzgün S, Kesim B, Tuncay O. Incidence of apical crack initiation and propagation during the removal of root canal filling material with ProTaper and Mtwo rotary nickel-titanium retreatment instruments and hand files. J Endod. 2014 Jul;40(7):1009-12. https://doi.org/10.1016/j.joen.2013.12.020

14. Betti LV, Bramante CM, Moraes IG, Bernardineli N, Garcia RB. Comparison of GPX with or without solvent and hand files in removing filling materials from root canals_an ex vivo study. Oral Surg Oral Med Oral Pathol Oral Radiol Endod. 2010 Nov;110(5):675-80. https://doi.org/10.1016/i.tripleo.2010.06.012 
15. Das S, De Ida A, Das S, Nair V, Saha N, Chattopadhyay S. Comparative evaluation of three different rotary instrumentation systems for removal of gutta-percha from root canal during endodontic retreatment: An in vitro study. J Conserv Dent. 2017 Sep-Oct;20(5):311-6. https://doi.org/10.4103/JCD.JCD_132_17

16. Leoni GB, Versiani MA, Pécora JD, Sousa-Neto MD. Micro-computed tomographic analysis of the root canal morphology of mandibular incisors. J Endod. 2014 May;40(5):710-6. https://doi.org/10.1016/i.joen.2013.09.003

17. De-Deus G, Belladonna FG, Silva EJ, Souza EM, Versiani MA. Critical appraisal of some methodological aspects of using micro-CT technology in the study of dentinal microcracks in endodontics. Int Endod J. 2016 Feb;49(2):216-9. https://doi.org/10.1111/iej.12570

18. Crozeta BM, Sousa-Neto MD, Leoni GB, Mazzi-Chaves JF, Silva-Sousa YTC, Baratto-Filho F. A micro-computed tomography assessment of the efficacy of rotary and reciprocating techniques for filling material removal in root canal retreatment. Clin Oral Investig. 2016 Nov;20(8):2235-40. https://doi.org/10.1007/s00784-016-1728-0

19. Yürüker S, Görduysus M, Küçükkaya S, Uzunoğlu E, Ilgın C, Gülen O, et al. Efficacy of combined use of different nickel-titanium files on removing root canal filling materials. J Endod. 2016 Mar;42(3):487-92. https://doi.org/10.1016/i.joen.2015.11.019

20. Rödig T, Reicherts P, Konietschke F, Dullin C, Hahn W, Hülsmann M. Efficacy of reciprocating and rotary NiTi instruments for retreatment of curved root canals assessed by micro-CT. Int Endod J. 2014 Oct;47(10):942-8. https://doi.org/10.1111/iej.12239

21. Roggendorf MJ, Legner M, Ebert J, Fillery E, Frankenberger R, Friedman S. Micro-CT evaluation of residual material in canals filled with Activ GP or GuttaFlow following removal with NiTi instruments. Int Endod J. 2010 Mar;43(3):200-9. https://doi.org/10.1111/j.1365-2591.2009.01659.x

22. Rached-Júnior FA, Sousa-Neto MD, Bruniera JF, Duarte MA, Silva-Sousa YT. Confocal microscopy assessment of filling material remaining on root canal walls after retreatment. Int Endod J. 2014 Mar;47(3):264-70. https://doi.org/10.1111/iej.12142

23. Hülsmann M, Bluhm V. Efficacy, cleaning ability and safety of different rotary NiTi instruments in root canal retreatment. Int Endod J. 2004 Jul;37(7):468-76. https://doi.org/10.1111/j.1365-2591.2004.00823.x

24. Bonaccorso A, Cantatore G, Condorelli GG, Schäfer E, Tripi TR. Shaping ability of four nickel-titanium rotary instruments in simulated S-shaped canals. J Endod. 2009 Jun;35(6):883-6. https://doi.org/10.1016/i.joen.2009.03.007

25. AlShwaimi E. Comparing ProFile Vortex to ProTaper Next for the efficacy of removal of root filling material: An ex vivo micro-computed tomography study. Saudi Dent J. 2018 Jan;30(1):63-9. https://doi.org/10.1016/i.sdentj.2017.10.007

26. Varela-Patiño P, Ibañez-Párraga A, Rivas-Mundiña B, Cantatore G, Otero XL, Martin-Biedma B. Alternating versus continuous rotation: a comparative study of the effect on instrument life. J Endod. 2010 Jan;36(1):157-9. https://doi.org/10.1016/i.joen.2009.09.023

27. Bürklein S, Hinschitza K, Dammaschke T, Schäfer E. Shaping ability and cleaning effectiveness of two single-file systems in severely curved root canals of extracted teeth: reciproc and WaveOne versus Mtwo and ProTaper. Int Endod J. 2012 May;45(5):449-61. https://doi.org/10.1111/j.1365-2591.2011.01996.x 